2 A decision analysis evaluating screening for kidney cancer using focused

\title{
renal ultrasound
}

4

5 Sabrina H. Rossi MBChB MPhil ${ }^{a, b, c}$, Tobias Klatte MD PhD ${ }^{b, d}$, Juliet A. Usher-Smith MB BChir

$6 \mathrm{PhD}^{\mathrm{e}}$, Kate Fife $\mathrm{MD}^{\mathrm{b}, \mathrm{c}}$, Sarah J. Welsh BMChB PhD ${ }^{\mathrm{b}, \mathrm{c}}$, Saeed Dabestani MD PhD ${ }^{\mathrm{f}}$, Axel Bex MD

7 PhD ${ }^{g, h}$, David Nicol MBBS ${ }^{i, j}$, Paul Nathan MBBS PhD ${ }^{k}$, Grant D. Stewart MBChB PhD ${ }^{a, b, c *}$,

8 Edward C.F. Wilson PhD ${ }^{1, \mathrm{~m} *}$

$9 \quad$ *joint senior authors

10

11 a Department of Surgery, University of Cambridge, Addenbrooke's Hospital, Cambridge

12 Biomedical Campus, Cambridge, UK

$13{ }^{b}$ Cambridge University Hospitals NHS Foundation Trust, Addenbrooke's Hospital,

14 Cambridge, UK

$15{ }^{\mathrm{C}}$ Cancer Research UK Cambridge Centre, University of Cambridge, Addenbrooke's Hospital,

16 Cambridge Biomedical Campus, Cambridge, UK

$17{ }^{\mathrm{d}}$ Department of Urology, Royal Bournemouth Hospital, Bournemouth, UK

18 e The Primary Care Unit, Department of Public Health and Primary Care, University of

19 Cambridge, Cambridge, UK

$20{ }^{f}$ Lund University, Skane University Hospital, Department of Clinical Sciences Lund, Lund,

21 Sweden

${ }^{\mathrm{g}}$ The Royal Free London NHS Foundation Trust, Specialist Centre for Kidney Cancer, UK 
$23{ }^{\mathrm{h}}$ Netherlands Cancer Institute, Division of Surgical Oncology, Department of Urology,

24 Amsterdam, The Netherlands

25 'Department of Urology, Royal Marsden Hospital, London, UK

26 j Institute of Cancer Research, London, UK

$27{ }^{k}$ Department of Oncology, Mount Vernon Cancer Centre, Northwood, UK

28 'Cambridge Centre for Health Services Research, University of Cambridge Institute of Public

29 Health, Forvie Site, Robinson Way, Cambridge, UK

$30 \mathrm{~m}$ Health Economics Group, Norwich Medical School, University of East Anglia, Norwich, UK

33 Corresponding authors:

34 Grant D Stewart, BSc MBChB PhD Edin, MA Cantab, FRCSEd (Urol)

35 Department of Surgery, University of Cambridge, Addenbrooke's Hospital, Cambridge

36 Biomedical Campus, CB2 0QQ, Cambridge, UK

37 Email: gds35@cam.ac.uk

38 Telephone: 01223245151

40 Edward CF Wilson BSc MSc PhD

41 Health Economics Group, Norwich Medical School, University of East Anglia, NR4 7TJ,

42 Norwich, UK

$43 \quad$ Email: Ed.Wilson@uea.ac.uk

44 Telephone: 01603593620

45 Running title: Decision analysis of screening for renal cancer 
47 Key words: Cost-effectiveness, Renal cell cancer, RCC, kidney cancer, Screening, Ultrasound

49 Funding: The Urology Foundation (SHR). Kidney Cancer UK (SHR and GDS). Renal Cancer Research Fund (SHR and GDS). CRUK Prevention Fellowship (C55650/A21464) (JUS). The funding sources had no role in data collection and analysis, nor the manuscript itself.

Financial Disclosure: PN has received consultancy fees from BMS, EUSA, Ipsen, MSD, Merck, Pfizer, Novartis. SDA has received honoraria from Pfizer and fees as medical advisor for Elypta AB. AB has received educational grants from Pfizer; consultancy fees from Pfizer, Roche, Novartis, BMS and EISAI. GDS has received educational grants from Pfizer, AstraZeneca and Intuitive Surgical; consultancy fees from Pfizer, Merck, EUSA Pharma and Cambridge Medical Robotics; Travel expenses from Pfizer and Speaker fees from Pfizer. All other authors have no financial disclosures.

60

Registration: Not applicable

62

Ethics: Health economics study not involving human participants therefore ethics approval 64 not required.

Acknowledgements: We would like to thank Professors Simon Griffin and Vicky Goh, as well as Ms Christy Watson, our patient representative, for their input and advice. We would also 
70 like to thank Kidney Cancer UK, The Renal Cancer Research Fund and The Urology

71 Foundation for their support.

72

73

74 Abstract word count: $300 / 300$

75

76 Manuscript word count: $2693 / 2500$

77

78

79

80

81

82

83

84

85

86

87 


\section{Structured abstract}

89

90

91

92

93

94

95

96

97

98

99

100

101

102

103 Outcome measures: Expected lifetime costs, quality adjusted life years (QALYs) and

104 incremental cost-effectiveness ratio (ICER), discounted at 3.5\%/annum.

105

106 Results: Given a prevalence of RCC of $0.34 \%$ (0.18-0.54\%), screening 60 year-old men

107

108

109

110

Background: Screening for renal cell carcinoma (RCC) has been identified as a key research priority; however, no randomised control trials have been performed. Value of information analysis can determine whether further research on this topic is of value.

Objectives: To determine (a) whether current evidence suggests screening is potentially cost-effective. If so, (b) in which age/sex groups, (c) identify evidence gaps and (d) estimate the value of further research to close those gaps.

Design, Setting, Participants: A decision model was developed evaluating screening in asymptomatic individuals in the UK. A National Health Service perspective was adopted.

Intervention: A single focused renal ultrasound scan compared with standard of care (no screening).

resulted in an ICER of $£ 18,092 / Q A L Y[€ 22,843 / Q A L Y]$. Given a prevalence of RCC of $0.16 \%$

(0.08-0.25\%), screening 60-year-old women resulted in an ICER of

$£ 37,327 / Q A L Y[€ 47,129 / Q A L Y]$. In the one-way sensitivity analysis, the ICER was

$<£ 30,000 / Q A L Y$ so long as the prevalence of RCC was $\geq 0.25 \%$ for men and $\geq 0.2 \%$ for women 
111 at age 60 years. Given a willingness to pay threshold of $£ 30,000 / Q A L Y[€ 37,878 / Q A L Y]$, the

112 population expected value of perfect information was $£ 194$ million[€244 million]

113 and $£ 97$ million[€123 million] for 60-year-old men and women respectively. The expected

114 value of perfect parameter information suggests the prevalence of RCC and stage shift

115 associated with screening are key research priorities.

116

117 Conclusion: Current evidence suggests one-off screening of 60 -year old men is potentially

118 cost-effective and that further research into this topic would be of value to society.

119

120 Patient Summary: Economic modelling suggests that screening 60-year-old men for kidney

121 cancer using ultrasound may be a good use of resources and that further research on this 122 topic should be performed.

123

124

125 Word count: $\mathbf{3 0 0 / 3 0 0}$

126

127 
128 Introduction

129 Cost-effectiveness analyses (CEA) are classically performed to aid decisions regarding the

130 value of implementing new interventions into a health service. More recently, value of

131 information analyses (VOI) of screening interventions have been undertaken using the

132 currently available evidence, prior to a large trial being undertaken, aiming to determine the

133 value of investing future funds into further research[1]. Indeed, VOI has been used to

134 examine uncertainty surrounding the optimal screening strategy for colorectal cancer and

135 therefore prioritise future research efforts[2].

136

137 Screening for renal cell carcinoma (RCC) has repeatedly been identified as a research

138 priority[3-6]. Over a quarter of individuals diagnosed with RCC have metastases at

139 presentation. Five-year age standardized relative survival for these individuals is $6 \%$

140 compared to $84 \%$ for those with stage I disease[7]. Ultrasound has been proposed as a

141 screening tool, as it is well tolerated, inexpensive and widely available[8]. National

142 abdominal aortic aneurysm (AAA) screening programs for 65-year-old men are established

143 in the UK and Sweden and have demonstrated that an ultrasound-based screening program

144 can be delivered in the community by trained technicians $[9,10]$. Observational studies

145 evaluating screening for RCC using ultrasound have been conducted. However, none were

146 randomised, and all were published more than a decade ago[11-18]. Due to the relatively

147 low prevalence of RCC in unselected asymptomatic individuals, a randomised controlled trial

148 (RCT) sufficiently powered to detect an impact on survival would need to recruit hundreds

149 of thousands of participants[11]. Therefore, we perform a decision analysis synthesizing the 
150 currently available evidence, with the aim of determining the value of performing further 151 research into this topic.

152

153 
154 Methods

155 Scope of the decision model

156

157 A cohort simulation model was developed adopting a UK National Health Service

158 perspective, consistent with Consolidated Health Economic Evaluation Reporting Standards

159 (Supplement)[19, 20]. The model compares screening (intervention) versus the standard of

160 care (no screening) in asymptomatic individuals from the general population. Screening

161 consists of a single focused renal ultrasound, delivered by technicians in the community,

162 similar to AAA screening[21]. If the ultrasound is reported as normal or as a simple cyst, the

163 patient is discharged. Any other abnormality is investigated with an outpatient urology clinic

$164 \pm$ CT as appropriate (Supplemental Figure 1). The primary outcomes are the incremental

165 costs (2016 fGBP), incremental quality adjusted life years (QALYs) and incremental cost-

166 effectiveness ratio (ICER) comparing one-off screening with no screening. The ICER was

167 defined as the mean incremental costs divided by the mean incremental QALYs. A cycle

168 length of one year and a lifetime time horizon were adopted. Costs and QALYs were

169 discounted at $3.5 \%$ /annum. The UK willingness to pay threshold of $£ 20,000-£ 30,000 / Q A L Y$

170 gained [€25,252-€37,878/QALY] was used; therefore, an ICER $>£ 30,000$ was considered not

171 to be cost-effective $[19,20]$.

172

173 Model structure

174

175 The model, which consisted of a decision tree with Markov models at each terminal node,

176 was developed in Microsoft Excel (2016). The decision tree demonstrates the disease status

177 (i.e. RCC, no RCC, benign incidental finding) and the test result (true positive/negative, false 
positive/negative). Figure 1 represents a simplified schematic of the Markov models (Supplemental Figures 2-7).

Model inputs

Model inputs were derived through comprehensive literature reviews and where no data were available, through structured expert elicitation (Table 1) [8, 11, 22, 23]. Further details are available in the Supplemental Methods.

A meta-analysis demonstrated that the pooled prevalence of RCC detected by ultrasound was more than twice as high in studies from Europe and North America compared to Asia $(0.17 \%(0.09-0.27 \%)$ vs $0.06(0.03-0.09 \%))(n=29,938)[11]$. Only one study, by Mihara et al., reported the prevalence of RCC by age and sex, which screened Japanese individuals from 1983 to 1996 (overall prevalence of RCC: 0.09\%)[14]. Although the study by Mihara et al. underestimates the true prevalence of RCC in a contemporary Western population, the relative prevalence by age and sex is likely to still be relevant[11, 14, 24]. Therefore, to derive likely prevalence rates in the UK by age and sex, the prevalence reported by Mihara et al. was used along with the results of the meta-analysis applied to the UK population reported by the Office for National Statistics (Table 1)[25].

The cost of AAA screening ultrasound in the UK is $£ 37.53$ [€47] [21]. In the base case, it was assumed screening renal ultrasound would have the same cost (Table 1). If ultrasound were to be performed by sonographers in secondary care, then it would be priced at $f 55$ (IQR $£ 38-£ 63)$ [€69], therefore this was evaluated in the sensitivity analysis[26]. 
202 No studies have evaluated the impact of screening for RCC on quality of life (QoL)[22].

203 Ultrasound screening for AAA and ovarian cancer was not associated with a disutility[27-31].

204 Therefore, ultrasound screening for RCC was assigned a disutility of 0 and this assumption

205 was tested in the sensitivity analysis.

206

207 Model analysis

209 The decision model was run with 3000 Monte Carlo simulations as this achieved stability of

210 results, defined as a coefficient of variation $<2 \%$ for the SE of the incremental net monetary

211 benefit[32]. In brief, this means a set of inputs was sampled from the respective

212 distributions, the model calculated and repeated 3000 times to generate an empirical

213 estimate of the uncertainty in cost-effectiveness. The ICER was evaluated for males and

214 females aged 40, 50 and 60 years as estimates for prevalence of RCC were available for

215 these groups based on the study by Mihara et al[14]. The population in whom screening is

216 most cost-effective was determined from this and used as the base case for all subsequent

217 analyses.

218

219 The expected value of perfect information (EVPI) and perfect parameter information (EVPPI)

220 were determined. The EVPI summarises the value of eliminating all parameter uncertainty

221 (i.e. perfect information), whereas the EVPPI summarises the value of eliminating individual

222 parameter uncertainty[33, 34]. Thus, the EVPI provides an upper limit for all future research expenditure regarding the decision problem. The EVPPI determines the value of eliminating

224 uncertainty in a parameter (or group of parameters), and so can be used to guide research 
225 priorities[34]. The population VOI statistics were based on the number individuals eligible

226 for screening[35]. The EVPPI was determined by running the simulation 1000 times for the

227 inner loop and 2000 times for the outer loop. An approximation of the impact of screening

228 was obtained by multiplying the incremental cost and QALYs of screening (per patient) by

229 the number of individuals eligible for screening.

230

231 
232 Results

233 Determining the most cost-effective screening population

234

235 The point estimate ICER is $<£ 30,000 / Q A L Y$ for 50 -year-old men and $<£ 20,000 / Q A L Y$ for 60 -

236 year-old men (Table 2). The ICER is $>£ 30,000 / Q A L Y$ for women of all ages, however the most

237 favourable ICER is observed for 60-year-old women. Therefore, age 60 years (males and

238 females) was chosen as the base case for all subsequent analyses.

240 Analysis of uncertainty

241

For 60 -year-old males, there is a $62 \%$ probability that the ICER is $<£ 20,000 / Q A L Y$ and a $66 \%$

243 probability that the ICER is $<£ 30,000 / Q A L Y$. For 60 -year-old females, there is a $44 \%$

244 probability that the ICER is $<£ 20,000 /$ QALY and a $56 \%$ probability that the ICER is

$245<£ 30,000 / \mathrm{QALY}$ (Supplemental Figure 8).

246

247 Sensitivity analyses

248

249 Cost-effectiveness improves as the prevalence increases and the cost of ultrasound

250 decreases (Table 3). Using $£ 37[€ 47]$ as the cost of ultrasound, the ICER remains

$251<£ 30,000 / Q A L Y$ so long as the prevalence of RCC is $\geq 0.25 \%$ for men and $\geq 0.2 \%$ for women

252 aged 60 years. Using our current estimates for the prevalence of RCC for 60 -year-old

253 women, the ICER is $\angle £ 30,000 / Q A L Y$ if the cost of screening ultrasound was reduced from

$254 £ 37$ to $\leq £ 30[€ 47$ to $\leq € 38]$. 
For 60-year-old males, the ICER remains $<£ 30,000 / Q A L Y$ so long as the disutility associated with screening is $\leq 0.05$ for one week (Supplemental Table 6). The ICER is $<£ 30,000 / Q A L Y$, if the specificity of ultrasound is $\geq 85 \%$ (Supplemental Table 7). Furthermore, in the base case, it was assumed that the combined prevalence of incidental benign conditions detected by screening would be $2.7 \%[11,17,18]$. The sensitivity analysis demonstrated that in 60 -yearold men, the ICER remains $<£ 30,000 / Q A L Y$ so long as the combined prevalence of other incidentally detected renal conditions is $\leq \mathbf{2 0 \%}$ (Supplemental Table 8 ). Sensitivity analyses for 60-year-old females are available in Supplemental Tables 6-8.

Value of information analysis

The number of individuals aged 60 years eligible to receive screening in the UK is 362,766 men/annum and 374,008 women/annum. Assuming a time horizon for which additional information is useful of ten years, this equates to a population that may benefit from screening of 3,122,576 men and 3,219,344 women (discounted at 3.5\%)[36]. Given a willingness to pay threshold of $£ 30,000 / Q A L Y$, the population EVPI is $£ 244,415,131$ $[€ 209,133,931]$ and $£ 97,263,108[€ 122,804,400]$ for 60-year-old males and females respectively (Supplemental Figure 9). The three parameters with the highest population EVPPI are the prevalence of RCC, the stage distribution of screen detected disease and the stage distribution of false negatives at screening (Figure 2). 
278 Impact on health services

279

280 Compared with no screening, screening 60-year-old males results in an overall expected

281 incremental cost per patient of $£ 44.55$ (cost of screening and treatment, discounted to

282 present value) over a 30-year lifetime[€56]. The number of males eligible to receive

283 screening in the UK is 362,766 per annum. Therefore, the present-value cost to the health

284 service would be $£ 16$ million[ $€ 20$ million] per cohort screened, over 30 years. However, the

285 majority of screening costs are accrued up front when screening occurs. The expected

286 incremental QALYs per patient is 0.0025 over 30 years (discounted to present value).

287 Therefore, that equates to 893 QALYs gained per cohort screened. For 60-year-old women,

288 screening would cost $£ 17$ million[ $€ 21$ million] and would lead to 467 additional QALYs per

289 cohort screened, over 30 years. 
291 Discussion

292 Screening for RCC has the potential to improve survival outcomes[4, 5]. However, as with

293 any screening program, there is also a potential for harm, including over-diagnosis, as well

294 as psychological and economic implications for patients and society. No RCTs of screening

295 for RCC have been undertaken[8]. We demonstrate that the population EVPI is $f 194$ million

296 and $\mathrm{f} 97$ million for 60-year-old men and women respectively. This suggests further research

297 is likely to be of good value to the funder, and should be focused on estimating the

298 prevalence of RCC and the stage shift associated with screening.

299

300 Determinants of cost-effectiveness

301

302 Using current evidence, this decision model suggests screening may be cost-effective in

303 males but not females, due to lower prevalence of RCC in the latter[11, 14]. The true

304 prevalence of RCC by age/sex in the UK is unknown. Sensitivity analysis suggests that

305 screening may be cost-effective if the prevalence is $\geq 0.25 \%$ for males and $\geq 0.2 \%$ for

306 females. A meta-analysis demonstrated the prevalence of RCC detected in middle-aged

307 Americans undergoing screening CT is $0.21 \%[24]$. Once again, the prevalence was not

308 reported by age/sex, however it may indeed be above the threshold identified by our

309 sensitivity analysis. Although beyond the scope of the present analysis, risk-stratified

310 screening may increase cost-effectiveness by targeting screening towards individuals with a

311 higher prevalence. At present there is a lack of specific, validated models to predict the risk

312 of RCC and further research is required to elucidate this [8, 37]. Similarly, screening for AAA

313 has been deemed cost-effective in men and not women, as the latter have a lower 
prevalence of the disease[28, 38]. However, there are important equity considerations associated with screening only one sex[39].

317 The cost of screening ultrasound is a modifiable factor which is a major determinant of cost-

318 effectiveness. Screening 60-year-old males remains cost-effective so long as the cost of

319 ultrasound is $<£ 60$. This is very likely as it is below the current cost of ultrasound performed

320 by a sonographer in secondary care[26]. When screening $60 y$ females, the ICER drops $<£ 30,000 / Q A L Y$ when the cost of ultrasound is reduced from $£ 37$ to $£ 30$. It is unclear whether the cost of technician-performed ultrasound may be reduced to this level. Renal ultrasound is technically more challenging to perform than aortic ultrasound. Accuracy is dependent on the size of the renal lesion and operator experience[40-42]. Our model suggests screening 60-year-old males remains cost-effective (i.e. ICER< $<30,000$ ) so long as the specificity of ultrasound is $\geq 85 \%$, and the prevalence of benign incidental findings at ultrasound is $\leq 20 \%$. All these conditions seem likely.

Potential harms of screening

331 Evidence on the impact of screening for RCC on QoL is lacking [8, 22]. In the base case, it was

332 assumed that undergoing screening ultrasound was not associated with a disutility, and this may contribute to the results demonstrating that the EVPPI for utilities was $f 0$. However, in

334 the sensitivity analysis, we showed that for 60-year-old men if the disutility associated with screening renal ultrasound is $\geq 0.05$ for one week, screening is no longer cost-effective. This

336 is because a small reduction in utility would be applied to such a large number of individuals receiving screening that it would outweigh any benefit to the small minority of patients in 
which RCC is detected. Therefore, it is essential that any future RCC screening studies evaluate the impact of screening on QoL.

Strengths and limitations

343 A strength of this work is that it is the first decision analysis of screening for RCC in

344 asymptomatic individuals. The model was designed with input from a multidisciplinary team

345 of RCC experts and a patient advocate. Importantly, the model incorporates the impact of

346 incidental findings detected by screening on cost-effectiveness. Systematic reviews were

347 undertaken to determine key model inputs and where data were not available, structured

348 expert elicitation was performed $[8,11,22,23]$. This ensures that uncertainty surrounding

349 parameter estimates was captured accurately, enabling reliable VOI[35].

The model represents a simplification of reality and shares some limitations inherent to all

352 CEAs. Due to structural assumptions within the model, it was not appropriate to assess the impact of ultrasound sensitivity on the ICER, as the stage distribution of false positives was determined by evidence from the literature. Some CEAs in other disease areas have overcome this by modelling the natural history of undiagnosed disease[32]. However, there are no existing data on the transition probabilities between undiagnosed RCC stages. As there are eleven potential health states (diagnosed and undiagnosed stage I T1a, I T1b, II, III,

358 IV, death) this would require 20 transition probabilities to be derived through expert elicitation. This would introduce undue uncertainty in the decision analysis, therefore it was

360 felt that the current structure was the most appropriate. High profile CEAs in other disease areas, such as screening for breast cancer, have also chosen to develop less complex models 
362 to minimize the assumptions and uncertainties arising from lack of data[43]. Life table

363 models and discrete event simulation models of screening for breast cancer have achieved

364 similar results $[43,44]$.

365

366 The CEA is limited by the absence of trial level data regarding certain model inputs.

367 Conversely, a major indication for the CEA was to determine if undertaking a trial of

368 screening was warranted on economic grounds. The prevalence of RCC was reported for a

369 limited number of age groups[11, 14]. It was not possible to evaluate repeated screening at

370 regular intervals, as screening studies scanned individuals only once. The model assumes

371 that cancer-specific mortality is determined by RCC stage and is the same in the screening

372 and no screening cohorts. Individuals with incidentally detected tumours have significantly

373 better survival compared to symptomatic patients, after adjusting for tumour grade and

374 stage[45]. Therefore, the model may underestimate the benefit of screening[46, 47].

375 However, as there are no RCTs demonstrating the effectiveness of screening, we do not

376 know if screening in a contemporary population would lead to a stage shift nor whether it

377 would impact survival. This consideration is particularly important as the number of

378 individuals undergoing abdominal imaging for other indications is rising[48]. Further trial

379 level data are required to quantify overdiagnosis and lead time bias. Additionally, there

380 were few data on the prevalence of benign incidental findings at screening, and their

381 associated impact on QoL or cost. We assigned a cost but no gain or loss of QALYs from

382 incidental findings. This simplification may underestimate the cost-effectiveness of

383 screening. 
385 Conclusion

386

387 Given the available evidence and the current willingness to pay threshold, our model

388 suggests that screening may be cost-effective in 60-year-old males. The prevalence of RCC

389 by age/sex is a major determinant of cost-effectiveness and represents a key research

390 priority, along with the stage shift associated with screening. Future work should focus on

391 evaluating the potential harms of screening including the impact on QoL, incidental findings

392 and overdiagnosis.

393

394

395

396

397

398

399

400

401

402

403

404

405 
406 Figures

407 Figure 1: Structure of the Markov model

408 Figure 1 represents a simplified schematic of the Markov models; further details can be

409 found in the Supplement. In brief, individuals without RCC can have a number of benign

410 incidental findings (asymptomatic calculi, hydronephrosis etc). Individuals with RCC can be

411 undiagnosed or diagnosed, by one of two ways: diagnosed via screening or opportunistically

412 within the health service. Once RCC is diagnosed, individuals can be classified into one of the

413 following five RCC health states: stage I T1a, stage I T1b, stage II, stage III and stage IV

414 based on established AJCC staging criteria. Newly diagnosed (ND) health states are tunnel

415 states reflecting costs and QALYs associated with the first year of diagnosis and treatment of

416 RCC, with follow up costs accrued and discounted up front, as previously described [49].

417 These tunnel states will transition into long-term health states, which represent metastasis

418 free (MF) states. Individuals will remain in each of these MF states until they progress (i.e.

419 metastatic progression). Stage IV disease (shown in the dotted box) encompasses both newly

420 diagnosed stage IV and metastatic recurrence. Stage IV disease may be subdivided into one

421 of the following health states based on treatment: individuals with no progression (NP) on

422 first line systemic therapy ("Stage IV, NP 1st line ST") and those with who do not receive

423 systemic therapy ("Stage IV, no ST"). These can lead to no progression on second line

424 therapy ("Stage IV, NP 2nd line ST"), no progression on third line therapy ("Stage IV, NP 3rd

425 line ST"), or progressive disease ("Stage IV, PD"). All health states can lead to "non RCC

426 death" (i.e. background mortality) or "RCC death" via the "Terminal" tunnel health state,

427 representing costs associated with the final year of life [49]. Arrows to these death health

428 states are not shown to maintain clarity in the diagram. 
Figure 1
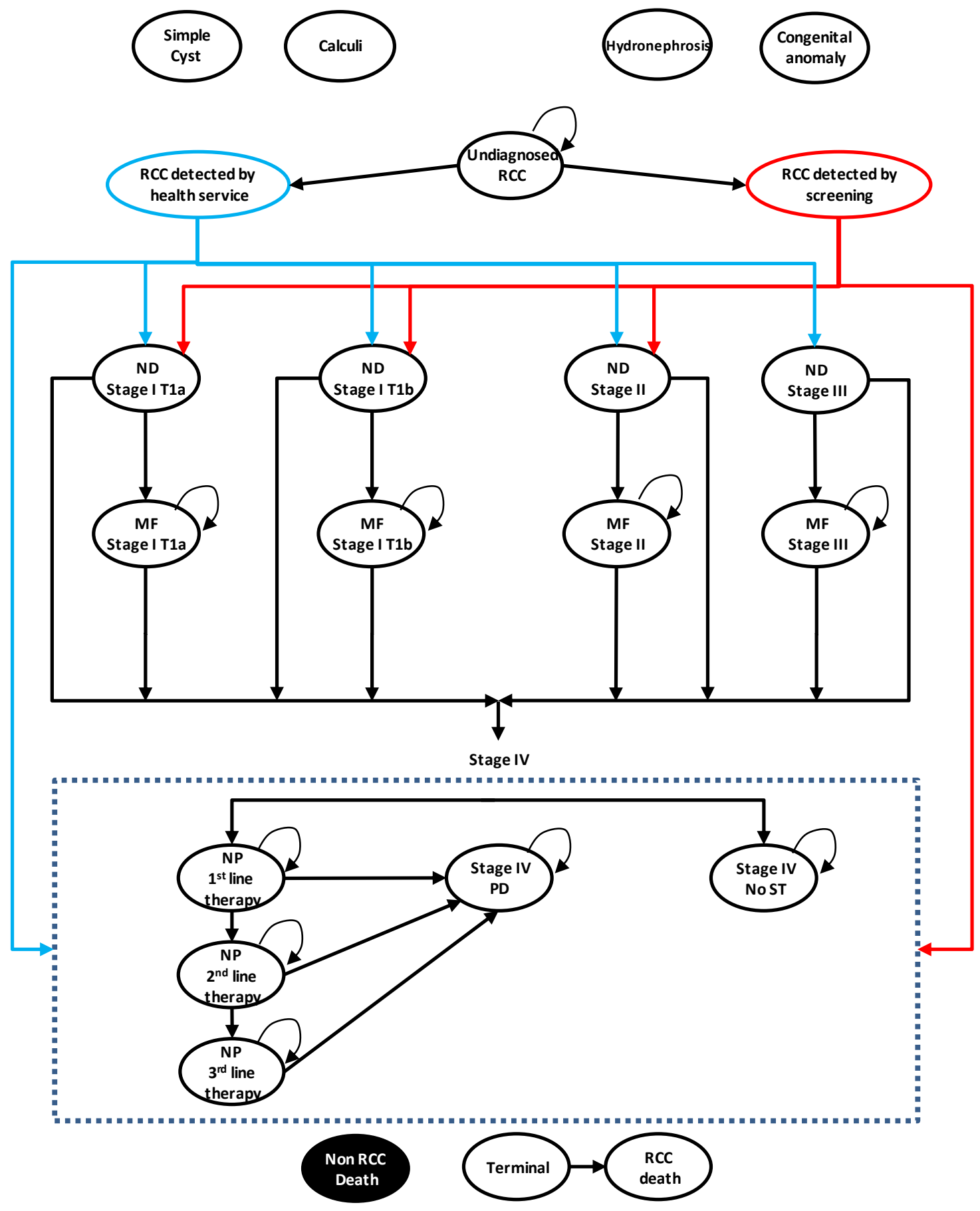
438 The population expected value of perfect parameter information (EVPPI) at a willingness to

439 pay threshold of $£ 30,000 / Q A L Y$ is shown for males and females aged 60 years. The

440 parameters investigated were: screening parameters, costs, utilities, transition probabilities

441 (TP) and stage distribution (SD) i.e. the proportion of individuals with RCC in each cancer

442 stage. The "\% receiving each therapy" refers to the proportion of individuals with RCC who

443 undergo each management option, for example, ablation, active surveillance, surgery (open

444 vs laparoscopic, partial vs radical) etc. "Utilities" refers to all utilities in the model, not just

445 the utility associated with screening. Note, the EVPPIs do not sum to the EVPI due to parameter correlation.

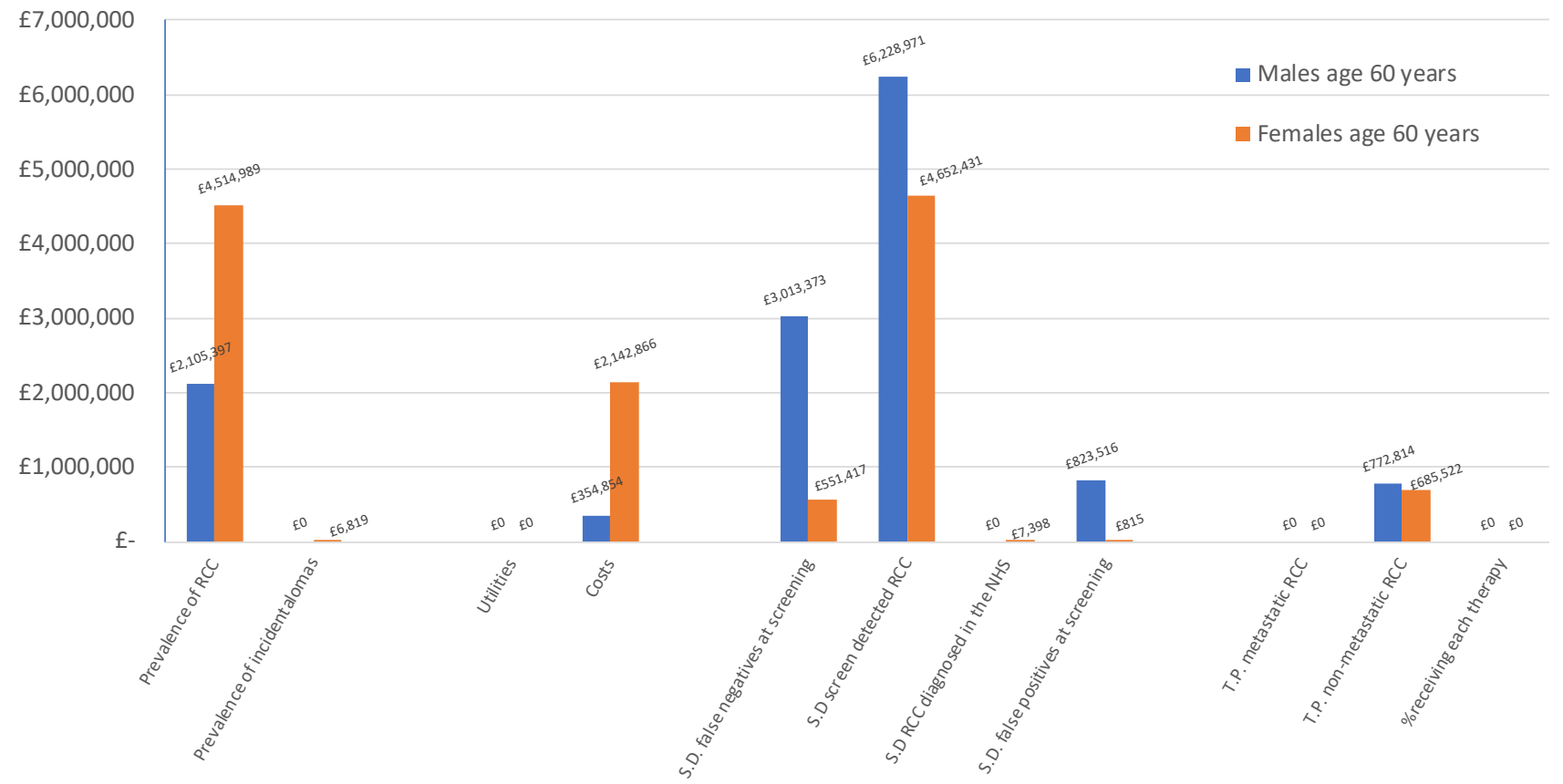


$450 \quad$ Tables

451 Table 1: Model inputs

452 For each model input, the mean estimate along with the 95\% confidence interval (CI) or

453 standard error (SE) is shown. For costs, the interquartile range (IQR) is reported as this is the

454 data provided by the national schedule of referencing costs. Parameters of the distribution

455 used in the probabilistic sensitivity analysis are demonstrated. For parameters derived

456 through expert elicitation, the median estimate and 95\% credibility intervals (Crl) are shown.

457 For modified Connor Mosimann distributions (mCM), the $a, b, L, U$ parameters are shown.

458 Medians do not sum to 1, however means do (data not shown). The ordering of Zed

459 parameters is critical to ensure correct calculation of probabilities, although this order may

460 not be the same as the logical order (stages I-IV). Further details regarding how transition

461 probabilities and summary costs were derived are available in the Supplement.

462

\begin{tabular}{|c|c|c|c|}
\hline Parameter & Source & Mean $(95 \% \mathrm{Cl})$ & Distribution \\
\hline \multicolumn{4}{|l|}{ Screening parameters } \\
\hline Sensitivity of ultrasound & {$[16,17,50,51]$} & $81.8 \%(52.3 \%-94.9 \%)$ & Beta $(9,2)$ \\
\hline Specificity of ultrasound & {$[16,17]$} & $98.2 \%(97.9 \%-98.5 \%)$ & Beta $(9771,177)$ \\
\hline $\begin{array}{c}\text { Specificity of CT following a positive } \\
\text { ultrasound }\end{array}$ & {$[17]$} & $98.9 \%(96.0 \%-99.7 \%)$ & Beta $(175,2)$ \\
\hline $\begin{array}{l}\text { Prevalence of asymptomatic } \\
\text { hydronephrosis }\end{array}$ & [11] & $0.48 \%(0.21-0.87 \%)$ & Beta $(8.05,1654.60)$ \\
\hline Prevalence of asymptomatic stones & {$[11]$} & $1.82 \%(0.59-3.64 \%)$ & Beta $(5.03,275.51)$ \\
\hline $\begin{array}{l}\text { Prevalence of other benign } \\
\text { asymptomatic findings on screening }\end{array}$ & {$[17,18]$} & $0.40 \%(0.30 \%-0.55 \%)$ & Beta $(40,9919)$ \\
\hline \multicolumn{4}{|l|}{ Prevalence of RCC } \\
\hline Prevalence in 40 -year-old males & & $0.14 \%(0.08-0.23 \%)$ & Beta $(14.24,9780.69)$ \\
\hline Prevalence in 50 -year-old males & & $0.23 \%(0.12-0.37 \%)$ & Beta $(12.58,5502.85)$ \\
\hline Prevalence in 60 -year-old males & Adapted from & $0.34 \%(0.18-0.54 \%)$ & Beta $(13.17,3905.89)$ \\
\hline Prevalence in 40-year-old females & {$[11,14,25]$} & $0.07 \%(0.04-0.11 \%)$ & Beta $(15.49,21892.72)$ \\
\hline Prevalence in 50 -year-old females & & $0.09 \%(0.05-0.14 \%)$ & Beta $(14.97,16729.45)$ \\
\hline Prevalence in 60-year-old females & & $0.16 \%(0.08-0.25 \%)$ & Beta $(12.30,8011.51)$ \\
\hline
\end{tabular}

\section{Stage distribution}

Parameter

Source $\quad$ Mean $(95 \% \mathrm{Cl}$ or $95 \% \mathrm{Crl})$

Distribution 
Screen detected RCC

Stage I T1a

Stage I T1b

Stage II

Stages I-II

Stage III

Stage IV

RCC detected by the health service

Stage I T1a

Stage I T1b

Stage I

Stages II

Stage III

Stage IV

Stage distribution of false positives

Stage I T1a

Stage I T1b

Stages II

Stage III

Stage IV

False negatives at screening

Stage I T1a
Stage I T1b
Stage IV
Stage II
Stage III

\section{Annual transition probabilities}

Parameter

Stage I T1a

Stage I T1a > Stage I T1a

Stage I T1a > Stage IV

Stage I T1a > RCC death

\section{Stage I T1b}

Stage I T1 $\mathrm{b}>$ Stage I T1 b

Stage I T1 $b>$ Stage IV

Stage I T1 $>$ RCC death

\section{Stage II}

Stage II > Stage II

Stage II > Stage IV

Stage II > RCC death

\section{Stage III}

Stage III > Stage III

Stage III > Stage IV

Stage III > RCC death
[52]

[54-56]

[54-56]

[54-56]

[54-56]

[54-56]

Structured

expert

elicitation

[23]

Source

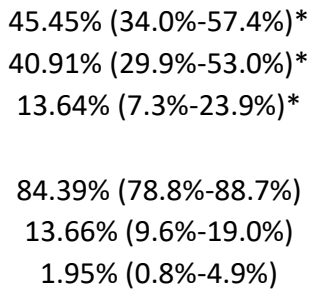

45.45\% (34.0\%-57.4\%)* 40.91\% (29.9\%-53.0\%)*

$13.64 \%$ (7.3\%-23.9\%)*

$84.39 \%$ (78.8\%-88.7\%)

$13.66 \%(9.6 \%-19.0 \%)$

$1.95 \%(0.8 \%-4.9 \%)$

$55.58 \%(54.12 \%-57.0 \%)^{\#}$ $44.42 \%(43.0 \%-45.9 \%)^{\#}$

44.21\% (42.96\%-45.46\%)

9.54\% (8.83\%-10.31\%)

$18.42 \%$ (17.47\%-19.42\%)

$27.83 \%$ (26.72\%-28.97\%)

$60.7 \%(57.1 \%-64.1 \%)$ $22.6 \%(19.7 \%-25.8 \%)$ $16.7 \%(14.2 \%-19.5 \%)$

$0 \%$

$0 \%$
Dirichlet $(30,27,9)$

Dirichlet $(173,28,4)$

Beta $(2511,2007)$

Beta $(2007,2511)$

Dirichlet

$(2678,578,1116,1686)$

Dirichlet $(451,168,124)$

$\operatorname{mCM}(6.72,2.41,0,1)$ $\operatorname{mCM}(0.35,0.49,0.157,1)$ $\operatorname{mCM}(0.64,0.40,0,1)$ $\operatorname{mCM}(10,10,0,1)$ $\mathrm{mCM}(-)$

Distribution

1-sum of other probabilities $0.0110(0.00552,0.0183) \quad$ Beta $(11.04,991.96)$ $0.00424(0.00346,0.00509) \quad$ Beta $(102.80,24165.20)$

1-sum of other probabilities $0.0326(0.0216-0.0457)$ $0.0198(0.0178-0.0219)$

Beta $(26.91,799.11)$ Beta $(349.31,17322.70)$

1-sum of other probabilities $0.0538(0.0371,0.0733)$ $0.0306(0.0131-0.0544)^{* *}$

Beta $(31.85,560.15)$ Beta $(7.86,250.99)$

1-sum of other probabilities $0.104(0.0810,0.129)$ $0.105(0.0828-0.131)^{* *}$
Beta $(64.69,559.31)$

Beta $(64.88,547.54)$ 


\section{No progression (NP) on $1^{\text {st }}$ line therapy}

NP on $1^{\text {st }}$ line therapy NP on $1^{\text {st }}$ line therapy

NP on $1^{\text {st }}$ line therapy> progressive disease

$0.274(0.242-0.307)$

NP on $1^{\text {st }}$ line therapy> death\$

No progression (NP) on $2^{\text {nd }}$ line therapy

NP on $2^{\text {nd }}$ line therapy $>$ NP on $2^{\text {nd }}$ line therapy

NP on $1^{\text {st }}$ line therapy> progressive disease

NP on $1^{\text {st }}$ line therapy> death\$

No progression (NP) on $3^{\text {rd }}$ line therapy

NP on $3^{\text {rd }}$ line therapy $>$ NP on $3^{\text {rd }}$ line therapy

NP on $3^{\text {rd }}$ line therapy $>$ progressive disease

NP on $3^{\text {rd }}$ line therapy> death $\$$

Stage IV, No systemic therapy

No systemic therapy> No systemic therapy

No systemic therapy $>$ death $^{\$}$

Progressive Disease (PD)

$\mathrm{PD}>\mathrm{PD}$

PD> death\$

Undiagnosed > Diagnosed RCC Opportunistic detection by health service

\section{Proportion undergoing each} management option

Management option Stage I RCC (T1a)

Active Surveillance

Percutaneous ablation Open partial nephrectomy Laparoscopic partial nephrectomy Robotic partial nephrectomy Open radical nephrectomy Laparoscopic radical nephrectomy Robotic radical nephrectomy

Stage I RCC (T1b)

Open partial nephrectomy Laparoscopic partial nephrectomy Robotic partial nephrectomy Open radical nephrectomy Laparoscopic radical nephrectomy Robotic radical nephrectomy

Stage II RCC

Open partial nephrectomy probabilities 1-sum of other

Dirichlet (201, 181, 351)

Beta $(177.04,775.96)$

Beta $(1739.46,1182.54)$

1-sum of other

probabilities

$[62,63]$

$0.451(0.420-0.482)$

Beta $(447.56,545.44)$

$[62,63]$

$0.489(0.458-0.520)$

Beta $(485.27,507.73)$

1-sum of other probabilities 0.646 (0.616-0.677)

Beta $(605.07,330.93)$

1-sum of other

probabilities $0.908(0.797-0.977)$

[65]

Structured

Expert

elicitation

[23]

Source

Proportion $(n / N)$

Expert opinion

Age Dependent

[66]

[67]

$0.024(77 / 3158)$

$0.145(235 / 1617)$

$0.138(223 / 1617)$

$0.306(494 / 1617)$

$0.032(52 / 1617)$

$0.364(588 / 1617)$

$0.015(25 / 1617)$

[67]

[67]

$0.074(108 / 1455)$

[67]

[67]

[67]

$0.014(21 / 1455)$

$0.056(81 / 1455)$

$0.104(151 / 1455)$

$0.715(1040 / 1455)$

[67]

$0.037(54 / 1455)$
Distribution

Beta $(33.58,3.42)$

Beta $(1.07,2.65)$

Beta $(77,3081)$

Dirichlet $(235,223,494,52$, $588,25)$

Dirichlet $(108,21,81,151$, $1040,54)$ 


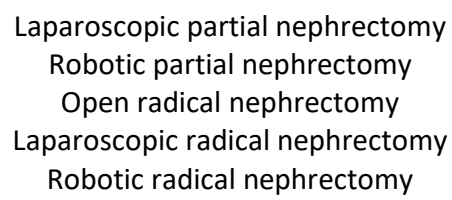

\section{Stage III RCC}

Open radical nephrectomy Laparoscopic or robotic radical nephrectomy

Stage IV RCC

Cytoreductive nephrectomy

Metastasectomy

Palliative radiotherapy for bone pain

Proportion of patients receiving no systemic therapy

Proportion receiving first line therapy Proportion of individuals on first line therapy who receive sunitinib

Proportion of individuals on first line therapy who receive second line therapy

Proportion of individuals on second line therapy who receive third line therapy

\section{Unit costs \\ Parameter}

Screening costs

Invitation (clerical staff time, postage and stationery, cost of obtaining patient details, office space and equipment)

Technician performed ultrasound

CT Abdomen \& Pelvis with contrast

\section{Assessment}

Clinical biochemistry

Haematology

Phlebotomy

Histopathology

$\mathrm{CT}$ chest with contrast

CT of three areas with contrast

CT brain

Outpatient renal biopsy

Urology outpatient clinic

Oncology clinic

MDT discussion
$0.003(4 / 1419)$

$0.011(16 / 1419)$

$0.409(580 / 1419)$

$0.540(766 / 1419)$

$0.018(26 / 1419)$

Expert Opinion

0.51

0.49

[68-74]

$[57,75]$

$[76,77]$

$[63,78-83]$

[83]

[83]

Source

$$
0.37(18,831 / 50,895)
$$$$
0.17(107 / 623)^{\sim ~}
$$

$0.12(137 / 1108)$

$0.28(104 / 365)$

$0.72(261 / 365)$

$0.43(527 / 1229)$

$0.47(123 / 261)$

$0.33(41 / 123)$

Mean (SE) or (IQR)

£1.94 [€2] (0.49)

£37.53 [€47] (9.38)

£115 [145€] (£88-f134)

$£ 1[1 €](£ 1-£ 1)$

$£ 3[€ 4](£ 2-£ 4)$

$£ 3[€ 4](£ 2-£ 4)$

f31 [€39] (£15-£36)

£102 [€129] (£71-£135)

$£ 121[€ 153](£ 88-£ 139)$

$102[€ 129](£ 71-£ 135)$

£158 [€199] (£125-£194)

f 105.19 [€133] (10.52)

£151 [€191] (£125-£194)

$£ 107[€ 135](£ 71-£ 131)$
Uniform $(0.35,0.65)$

Uniform $(0.65,0.35)$

Dirichlet $(27,4,16,580$, $766,26)$

Beta (18831, 32064)

Beta $(107,516)$

Beta $(137,971)$

Beta $(104,261)$

Beta $(261,104)$

Beta $(527,702)$

Beta $(123,138)$

Beta $(41,82)$

Distribution

Gamma (16, 0.12)

Gamma (16, 2.35)

Gamma $(10.59,10.66)$

\section{Constant}

Gamma $(4.08,0.77)$

Gamma $(4.08,0.77)$

Gamma (2.66, 10.25)

Gamma (4.70, 22.77)

Gamma $(9.01,12.86)$

Gamma (4.70, 22.77)

Gamma $(9.72,16.72)$

Gamma $(100,1.05)$

Gamma $(9.72,16.72)$

Gamma $(5.15,20.33)$ 


\section{Management}

Percutaneous Cryoablation

Percutaneous, Microwave or

Radiofrequency Ablation

Laparoscopic nephrectomy (partial or radical) Cost of surgery and health care costs over one year

Open nephrectomy (partial or radical) Cost of surgery and health care costs over one year

Robotic nephrectomy (partial or radical)

Cost of surgery and health care costs over one year

Cytoreductive nephrectomy

Cost of surgery and health care costs over one year

Metastasectomy for thoracic metastases

Metastasectomy for abdominal metastases

Radiotherapy (preparation and delivery)

\section{Annual drug costs}

Sunitinib

Pazopanib

Everolimus

Axitinib

Cabozantinib

Nivolumab

Lenvatinib \& Everolimus

Contact with the health services due to adverse events (annual cost for pazopanib)

Contact with the health services due to adverse events (annual cost for all other therapies)

\section{Summary costs for health states}

Incidental hydronephrosis or renal

$$
\text { stone }
$$

Incidental congenital renal anomaly

Newly diagnosed Stage I T1a

Newly diagnosed Stage I T1b
$£ 5,372[€ 6,783]$

$(£ 3,444-£ 6,563)$

$£ 2,952[€ 3,727]$

$(£ 1,706-f 3,559)$

$£ 6,581[€ 8,309]$

(£6,001- £7123)

$£ 8,021[€ 10,127]$

$(£ 7,000-f 8,946)$

$£ 6,534[€ 8,250]$

(£5,972-£7,059)

$£ 9,938[€ 12,548]$

(993.8)

[85]

[26]

$£ 6,514[€ 8,225]$

$(£ 4,973-£ 7,655)$

$£ 4,101[€ 5,178]$

(£2,538-£5,345)

£388 [€490]

(£279-£483)

$£ 16,120$

$[€ 20,353]$

$£ 16,304$

$[€ 20,585]$

£25,765

[€32,531]

$£ 29,543$

$[€ 37,301]$

$£ 54,002$

$[€ 68,183]$

$£ 57,625$

$[€ 72,757]$

f51,668

$[€ 65,236]$

[86, 91]

[81]

£1,622 (162.2)

$[€ 2,048]$

[81]

£2,144 (214.4)

$[€ 2,707]$
Gamma (100, 99.38)

Gamma (4.67, 1113.35)

Gamma $(3.66,756.08)$

Gamma $(62.33,105.59)$

Gamma (30.55, 262.55)

Gamma $(65.32,100.03)$

Gamma $(10.08,637.65)$

Gamma $(3.57,1160.30)$

Gamma $(6.34,61.79)$
Constant

Constant

Constant

Constant

Constant

Constant

Constant

Beta $(100,16.22)$
Beta $(100,21.44)$
£220

[€278]

£105

[€133]

$£ 7,510$

[€9,482]

$f 6,821$

[€8,612] 


\begin{tabular}{|c|c|c|}
\hline \multicolumn{2}{|l|}{ Newly diagnosed Stage II } & $\begin{array}{c}£ 8,110 \\
{[€ 10,240]}\end{array}$ \\
\hline \multicolumn{2}{|l|}{ Newly diagnosed Stage III } & $\begin{array}{c}£ 8,595 \\
{[€ 10,852]}\end{array}$ \\
\hline \multirow{2}{*}{\multicolumn{2}{|c|}{$\begin{array}{l}\text { Metastasis free Stage I-III } \\
\text { Undiagnosed RCC }\end{array}$}} & f0 \\
\hline & & $£ 0$ \\
\hline \multicolumn{2}{|l|}{ False positive $(<4 \mathrm{~cm})$} & $\begin{array}{c}£ 6,889 \\
{[€ 8,698]}\end{array}$ \\
\hline \multicolumn{2}{|l|}{ False positive $(4-7 \mathrm{~cm})$} & $\begin{array}{c}£ 7,259 \\
{[€ 9,165]}\end{array}$ \\
\hline \multicolumn{2}{|l|}{ False positive $(>7 \mathrm{~cm})$} & $\begin{array}{c}€ 7,622 \\
{[€ 9,624]}\end{array}$ \\
\hline \multicolumn{2}{|l|}{ Newly diagnosed stage IV } & $\begin{array}{c}£ 4,555 \\
{[€ 5,751]}\end{array}$ \\
\hline \multicolumn{2}{|l|}{$\begin{array}{l}\text { Newly diagnosed metastatic } \\
\text { recurrence }\end{array}$} & $\begin{array}{c}€ 759 \\
{[€ 958]}\end{array}$ \\
\hline \multicolumn{2}{|l|}{ No progression on 1st line ST } & $\begin{array}{c}£ 19,244 \\
{[€ 24,297]}\end{array}$ \\
\hline \multicolumn{2}{|l|}{ Vo progression on 2 nd line ST } & $\begin{array}{c}£ 47,041 \\
{[€ 59,394]}\end{array}$ \\
\hline \multicolumn{2}{|l|}{ Vo progression on 3rd line ST } & $\begin{array}{c}£ 47,041 \\
{[€ 59,394]}\end{array}$ \\
\hline Stage IV, no systemic therapy & {$[77,81]$} & $\begin{array}{c}£ 1,428 \\
{[€ 1,803]}\end{array}$ \\
\hline Progressive disease & {$[77,81]$} & $\begin{array}{c}£ 1,690 \\
{[€ 2,134]}\end{array}$ \\
\hline Terminal care costs & [92] & $\begin{array}{l}£ 11,616 \\
{[€ 14,666]}\end{array}$ \\
\hline
\end{tabular}

\section{Utilities}

Parameter

Screening Ultrasound

No cancer

Undiagnosed Cancer

Newly diagnosed Stage I T1a

Newly diagnosed I T1b

Newly diagnosed Stage II

Newly diagnosed Stage III

Metastasis free Stages I-III

False positive Stage I T1a

False positive Stage I T1b

False positive Stage II

Stage IV, NP on $1^{\text {st }}$ line therapy Stage IV, NP on $2^{\text {nd }}$ line therapy

Stage IV, NP on $3^{\text {rd }}$ line therapy

Stage IV, NST

Progressive Disease

Terminal, RCC Death and Non-RCC
Source

Assumption

Assumption

Assumption

Clinical expert

opinion based

on $[22,93]$

Assumption

$\begin{array}{ll}\text { [94-98] } & 0.78\end{array}$

[77] 0.70

Assumption

based on [77]

[77]

[77]

Assumption
0.934 \$

$0.934^{\$ \$}$

$0.869^{\# \#}$

Mean

1

Varied in sensitivity

analysis

1

$0.934^{\$ \$}$

$0.934 \$$

$0.869^{\# \#}$

$0.869^{\# \#}$

1

0.70

0.70

0.69

0.61

0
Distribution

Constant

Constant

Constant

Beta $(5.64,0.40)$

Beta $(5.64,0.40)$

Beta $(12.28,1.86)$

Beta $(12.28,1.86)$

Constant

Beta $(5.64,0.40)$

Beta $(5.64,0.40)$

Beta $(12.28,1.86)$

Beta $(1337.7,377.3)$

Beta $(29.3,12.56)$

Beta $(29.3,12.56)$

Beta $(500.31,222.68)$

Beta $(441.03,281.97)$

Constant

$463 \sim$ Small or atrophic kidneys, aplasia, dysplasia, duplication or horseshoe kidney 
465 \#Proportions of those stage I

$466 * *$ Relative survival, therefore this was converted to absolute survival using the age dependent probability of

467 background mortality (see Supplement for details).

468 \$Overall survival data was utilised to calculate the transition probability from each health state to death. This

469 value was subsequently adjusted based on known age dependent background mortality to derive the

470 transition probability for RCC death

$471 \sim \sim$ It was assumed $28.8 \%$ (17/59) of individuals undergo surgical management for thoracic metastases and

$47271.2 \%(42 / 59)$ for abdominal metastases [75].

$473 \$$ \$Equivalent to a utility of 0.737 for 3 months and a utility of 1 for 9 months

$474 \quad \#$ Equivalent to a utility of 0.737 for 6 months and a utility of 1 for 6 months 
476 Table 2: Baseline results

477 The incremental costs (cost of screening and treatment), quality adjusted life years (QALYs)

478 and incremental cost-effectiveness ratio (ICER) per person screened is shown for each age

479 and sex.

\begin{tabular}{ccccccc}
\hline & \multicolumn{3}{c}{ Males } & \multicolumn{3}{c}{ Females } \\
\cline { 2 - 7 } & 40 years & 50 years & 60 years & 40 years & 50 years & 60 years \\
\hline Prevalence & $0.14 \%$ & $0.23 \%$ & $0.34 \%$ & $0.07 \%$ & $0.09 \%$ & $0.16 \%$ \\
of RCC & $(0.08-0.23 \%)$ & $(0.12-0.37 \%)$ & $(0.18-0.54 \%)$ & $(0.04-0.11 \%)$ & $(0.05-0.14 \%)$ & $(0.08-0.25 \%)$ \\
Incremental costs & $£ 47.06$ & $£ 45.69$ & $£ 44.55$ & $£ 47.61$ & $£ 46.99$ & $£ 46.56$ \\
Incremental QALYs & 0.00155 & 0.00205 & 0.00246 & 0.000809 & 0.000937 & 0.00125 \\
ICER & $£ 30,367$ & $£ 22,277$ & $£ 18,092$ & $£ 58,819$ & $£ 50,160$ & $£ 37,327$ \\
\hline
\end{tabular}

480

481 
482 Table 3: Results of the two-way sensitivity analysis of age, sex, prevalence of RCC and cost of screening ultrasound

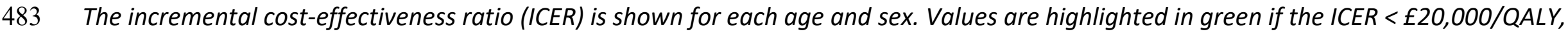

484 amber if the ICER $£ 20,000-£ 30,000 / Q A L Y$ and red if the ICER $>£ 30,000 / Q A L Y$.

485

\begin{tabular}{|c|c|c|c|c|c|c|}
\hline \multirow[b]{2}{*}{ Prevalence } & \multicolumn{3}{|c|}{ Males } & \multicolumn{3}{|c|}{ Females } \\
\hline & 40 years & 50 years & 60 years & 40 years & 50 years & 60 years \\
\hline 0.0005 & f79,384 & $£ 99,763$ & $£ 134,251$ & $f 77,526$ & f93,379 & f123,795 \\
\hline 0.001 & f41,969 & $£ 49,599$ & $£ 69,003$ & $£ 38,733$ & $f 44,318$ & $£ 57,667$ \\
\hline 0.0015 & f30,359 & $£ 31,496$ & $£ 46,545$ & $£ 25,266$ & $£ 28,901$ & $£ 37,799$ \\
\hline 0.002 & $£ 20,832$ & $£ 25,143$ & $£ 33,320$ & $£ 18,935$ & $£ 22,306$ & $£ 29,603$ \\
\hline 0.0025 & f14,949 & $£ 18,784$ & $£ 26,377$ & $£ 14,592$ & $£ 18,170$ & $£ 22,058$ \\
\hline 0.003 & $f 12,969$ & $£ 15,546$ & $£ 21,163$ & $£ 12,212$ & $£ 14,615$ & $£ 19,429$ \\
\hline 0.0035 & £9,961 & $£ 12,046$ & $£ 16,676$ & $f 10,474$ & $f 12,308$ & $£ 15,710$ \\
\hline 0.004 & $£ 9,154$ & $£ 11,830$ & $£ 15,644$ & $f 8,920$ & $£ 10,399$ & $£ 13,846$ \\
\hline 0.0045 & f7,803 & $£ 9,990$ & $£ 14,633$ & f7,533 & $£ 8,897$ & $£ 11,548$ \\
\hline 0.005 & $f 6,862$ & $f 8,433$ & $£ 12,774$ & $f 6,611$ & $f 7,957$ & $f 10,285$ \\
\hline 0.0055 & $f 6,209$ & $f 8,232$ & $f 11,438$ & $f 6,152$ & $£ 7,413$ & $£ 9,151$ \\
\hline 0.006 & $f 5,651$ & f7,786 & $£ 10,123$ & $f 5,716$ & $f 6,863$ & $f 8,862$ \\
\hline \multicolumn{7}{|l|}{ Cost of US } \\
\hline$£ 70$ & $£ 47,863$ & $£ 34,319$ & $£ 34,000$ & $£ 91,772$ & $f 85,491$ & $f 69,092$ \\
\hline$f 60$ & $£ 40,587$ & $£ 31,717$ & $£ 29,317$ & $f 81,603$ & f76,915 & $f 59,227$ \\
\hline$f 50$ & $£ 35,309$ & $£ 26,187$ & $£ 24,134$ & f68,069 & $f 62,299$ & $£ 45,981$ \\
\hline$f 40$ & $£ 29,199$ & $£ 21,161$ & $£ 18,443$ & $f 57,431$ & $f 52,414$ & $£ 38,759$ \\
\hline$f 30$ & $f 23,165$ & $£ 18,479$ & $£ 16,061$ & $£ 45,740$ & $£ 42,234$ & $£ 28,754$ \\
\hline$£ 20$ & f16,371 & $£ 13,141$ & $£ 11,340$ & $£ 37,756$ & f34,387 & $£ 23,083$ \\
\hline
\end{tabular}


486

487

488

489

490

491

492

493

494

495

496

497

498

499

500

501

502

503

504

505

506

507

\section{References}

[1] Chalmers I, Bracken MB, Djulbegovic B, Garattini S, Grant J, Gulmezoglu AM, et al. How to increase value and reduce waste when research priorities are set. Lancet. 2014;383:15665.

[2] Hassan C, Hunink MG, Laghi A, Pickhardt PJ, Zullo A, Kim DH, et al. Value-of-information analysis to guide future research in colorectal cancer screening. Radiology. 2009;253:745-

52.

[3] Motzer RJ. Perspective: What next for treatment? Nature. 2016;537:S111.

[4] Jones J, Bhatt J, Avery J, Laupacis A, Cowan K, Basappa N, et al. The kidney cancer research priority-setting partnership: Identifying the top 10 research priorities as defined by patients, caregivers, and expert clinicians. Can Urol Assoc J. 2017;11:379-87.

[5] The Kidney Cancer UK patient survey report 2018. In: UK KC, editor.2018.

[6] Rossi SH, Blick C, Handforth C, Brown JE, Stewart GD, Renal Cancer Gap Analysis C. Essential Research Priorities in Renal Cancer: A Modified Delphi Consensus Statement. Eur Urol Focus. 2019.

[7] Five-Year Relative Survival by Stage, Adults (Aged 15-99 Years), Former Anglia Cancer Network, 2002-2006. Cancer Research UK; 2014.

[8] Rossi SH, Klatte T, Usher-Smith J, Stewart GD. Epidemiology and screening for renal cancer. World J Urol. 2018;36:1341-53.

[9] Darwood R, Earnshaw JJ, Turton G, Shaw E, Whyman M, Poskitt K, et al. Twenty-year review of abdominal aortic aneurysm screening in men in the county of Gloucestershire, United Kingdom. J Vasc Surg. 2012;56:8-13. 
508 [10] Wanhainen A, Hultgren R, Linne A, Holst J, Gottsater A, Langenskiold M, et al. Outcome

509 of the Swedish Nationwide Abdominal Aortic Aneurysm Screening Program. Circulation.

$510 \quad 2016 ; 134: 1141-8$.

511 [11] Rossi SH, Hsu R, Blick C, Goh V, Nathan P, Nicol D, et al. Meta-analysis of the prevalence

512 of renal cancer detected by abdominal ultrasonography. Br J Surg. 2017;104:648-59.

513 [12] Spouge AR, Wilson SR, Wooley B. Abdominal sonography in asymptomatic executives:

514 prevalence of pathologic findings, potential benefits, and problems. J Ultrasound Med. 515 1996;15:763-7; quiz 9-70.

516 [13] Fujii Y, Ajima J, Oka K, Tosaka A, Takehara Y. Benign renal tumors detected among 517 healthy adults by abdominal ultrasonography. Eur Urol. 1995;27:124-7.

518 [14] Mihara S, Kuroda K, Yoshioka R, Koyama W. Early detection of renal cell carcinoma by

519 ultrasonographic screening--based on the results of 13 years screening in Japan. Ultrasound 520 Med Biol. 1999;25:1033-9.

521 [15] Tsuboi N, Horiuchi K, Kimura G, Kondoh Y, Yoshida K, Nishimura T, et al. Renal masses 522 detected by general health checkup. Int J Urol. 2000;7:404-8.

523 [16] Mizuma Y, Watanabe Y, Ozasa K, Hayashi K, Kawai K. Validity of sonographic screening 524 for the detection of abdominal cancers. J Clin Ultrasound. 2002;30:408-15.

525 [17] Filipas D, Spix C, Schulz-Lampel D, Michaelis J, Hohenfellner R, Roth S, et al. Screening 526 for renal cell carcinoma using ultrasonography: a feasibility study. BJU Int. 2003;91:595-9.

527 [18] Malaeb BS, Martin DJ, Littooy FN, Lotan Y, Waters WB, Flanigan RC, et al. The utility of 528 screening renal ultrasonography: identifying renal cell carcinoma in an elderly asymptomatic 529 population. BJU Int. 2005;95:977-81.

530 [19] NICE. National Institute for Health and Care Excellence Guide to the methods of 531 technology appraisal. 2013. 
532 [20] Husereau D, Drummond M, Petrou S, Carswell C, Moher D, Greenberg D, et al.

533 Consolidated Health Economic Evaluation Reporting Standards (CHEERS) statement. Clin

534 Ther. 2013;35:356-63.

535 [21] Thompson SG, Brown LC, Sweeting MJ, Bown MJ, Kim LG, Glover MJ, et al. Systematic

536 review and meta-analysis of the growth and rupture rates of small abdominal aortic

537 aneurysms: implications for surveillance intervals and their cost-effectiveness. Health

538 Technol Assess. 2013;17:1-118.

539 [22] Rossi SH, Klatte T, Stewart GD. Quality of life outcomes in patients with localised renal

540 cancer: a literature review. World J Urol. 2018.

541 [23] Rossi S.H. BC, Nicol D., Stewart G.D., Wilson E.C.F. Expert elicitation to inform a cost

542 effectiveness analysis of screening for renal cancer. Value Health. 2019; In press.

543 [24] Fenton JJ, Weiss NS. Screening computed tomography: will it result in overdiagnosis of

544 renal carcinoma? Cancer. 2004;100:986-90.

545 [25] Population Estimates for UK, England and Wales, Scotland and Northern Ireland: Mid-

546 2017. In: Statistics OfN, editor.2017.

547 [26] NHS reference costs 2015 to 2016. In: Care DoHaS, editor.2016.

548 [27] Ashton HA, Buxton MJ, Day NE, Kim LG, Marteau TM, Scott RA, et al. The Multicentre

549 Aneurysm Screening Study (MASS) into the effect of abdominal aortic aneurysm screening

550 on mortality in men: a randomised controlled trial. Lancet. 2002;360:1531-9.

551 [28] Glover MJ, Kim LG, Sweeting MJ, Thompson SG, Buxton MJ. Cost-effectiveness of the

552 National Health Service Abdominal Aortic Aneurysm Screening Programme in England. Br J

553 Surg. 2014;101:976-82.

554 [29] Kim LG, Thompson SG, Briggs AH, Buxton MJ, Campbell HE. How cost-effective is

555 screening for abdominal aortic aneurysms? J Med Screen. 2007;14:46-52. 
556

557

558

559

560

561

562

563

564

565

566

567

568

569

570

571

572

573

574

575

576

577

578

579

[30] Barrett J, Jenkins V, Farewell V, Menon U, Jacobs I, Kilkerr J, et al. Psychological

morbidity associated with ovarian cancer screening: results from more than 23,000 women

in the randomised trial of ovarian cancer screening (UKCTOCS). BJOG. 2014;121:1071-9.

[31] Reade CJ, Riva JJ, Busse JW, Goldsmith CH, Elit L. Risks and benefits of screening

asymptomatic women for ovarian cancer: a systematic review and meta-analysis. Gynecol

Oncol. 2013;130:674-81.

[32] Wilson ECF, Usher-Smith JA, Emery J, Corrie P, Walter FM. A Modeling Study of the Cost-Effectiveness of a Risk-Stratified Surveillance Program for Melanoma in the United Kingdom. Value Health. 2018;21:658-68.

[33] Briggs A, Claxton K., Sculpher M. Decision analytic modelling for health economic evaluation: Oxford University Press; 2011.

[34] Wilson E.C.F. AK. From evidence-based economics to economics-based evidence: using systematic review to inform the design of future research. In: Shemilt I. MM, Vale L., Marsh K., Donaldson C., editor. Evidence-Based Decisions and Economics Health care, social welfare, education and criminal justice: Blackwell Publishing Ltd.; 2010.

[35] Wilson E, Abrams K. From Evidence Based Economics to Economics Based Evidence:

Using Systematic Review to inform the design of future research. In: Shemilt I, Mugford M, Vale L, Marsh K, Donaldson C, editors. Evidence Based Economics. London: Blackwell Publishing; 2010.

[36] Philips Z, Claxton K, Palmer S. The half-life of truth: what are appropriate time horizons for research decisions? Med Decis Making. 2008;28:287-99.

[37] Scelo G, Muller DC, Riboli E, Johannson M, Cross AJ, Vineis P, et al. KIM-1 as a bloodbased marker for early detection of kidney cancer: a prospective nested case-control study. Clin Cancer Res. 2018. 
580

581

582

583

584

585

586

587

588

589

590

591

592

593

594

595

596

597

598

599

600

601

[38] Sweeting MJ, Masconi KL, Jones E, Ulug P, Glover MJ, Michaels JA, et al. Analysis of clinical benefit, harms, and cost-effectiveness of screening women for abdominal aortic aneurysm. Lancet. 2018.

[39] Current UK National Screening Committee Recommendations. UK National Screening Committee 2016.

[40] Warshauer DM, McCarthy SM, Street L, Bookbinder MJ, Glickman MG, Richter J, et al. Detection of renal masses: sensitivities and specificities of excretory urography/linear tomography, US, and CT. Radiology. 1988;169:363-5.

[41] Jamis-Dow CA, Choyke PL, Jennings SB, Linehan WM, Thakore KN, Walther MM. Small $(<$ or $=3-\mathrm{cm})$ renal masses: detection with CT versus US and pathologic correlation. Radiology. 1996;198:785-8.

[42] Schmidt T, Hohl C, Haage P, Blaum M, Honnef D, Weibeta C, et al. Diagnostic accuracy of phase-inversion tissue harmonic imaging versus fundamental B-mode sonography in the evaluation of focal lesions of the kidney. AJR Am J Roentgenol. 2003;180:1639-47.

[43] Pashayan N, Morris S, Gilbert FJ, Pharoah PDP. Cost-effectiveness and Benefit-to-Harm Ratio of Risk-Stratified Screening for Breast Cancer: A Life-Table Model. JAMA Oncol. 2018. [44] Gray E, Donten A, Karssemeijer N, van Gils C, Evans DG, Astley S, et al. Evaluation of a Stratified National Breast Screening Program in the United Kingdom: An Early Model-Based Cost-Effectiveness Analysis. Value Health. 2017;20:1100-9.

[45] Ficarra V, Prayer-Galetti T, Novella G, Bratti E, Maffei N, Dal Bianco M, et al. Incidental detection beyond pathological factors as prognostic predictor of renal cell carcinoma. Eur Urol. 2003;43:663-9. 
602 [46] Ficarra V, Schips L, Guille F, Li G, De La Taille A, Prayer Galetti T, et al. Multiinstitutional

603 European validation of the 2002 TNM staging system in conventional and papillary localized

604 renal cell carcinoma. Cancer. 2005;104:968-74.

605 [47] Patard JJ, Rodriguez A, Rioux-Leclercq N, Guille F, Lobel B. Prognostic significance of the 606 mode of detection in renal tumours. BJU Int. 2002;90:358-63.

607 [48] Welch HG, Skinner JS, Schroeck FR, Zhou W, Black WC. Regional Variation of Computed 608 Tomographic Imaging in the United States and the Risk of Nephrectomy. JAMA Intern Med. 6092017.

610 [49] Wilson EC, Emery JD, Kinmonth AL, Prevost AT, Morris HC, Humphrys E, et al. The cost-

611 effectiveness of a novel SIAscopic diagnostic aid for the management of pigmented skin

612 lesions in primary care: a decision-analytic model. Value Health. 2013;16:356-66.

613 [50] Halpern JA, Chughtai B, Ghomrawi H. Cost-effectiveness of Common Diagnostic

614 Approaches for Evaluation of Asymptomatic Microscopic Hematuria. JAMA Intern Med.

$615 \quad 2017 ; 177: 800-7$.

616 [51] Corcoran AT, Russo P, Lowrance WT, Asnis-Alibozek A, Libertino JA, Pryma DA, et al. A

617 review of contemporary data on surgically resected renal masses--benign or malignant?

618 Urology. 2013;81:707-13.

619 [52] Thorstenson A, Harmenberg U, Lindblad P, Holmstrom B, Lundstam S, Ljungberg B.

620 Cancer Characteristics and Current Treatments of Patients with Renal Cell Carcinoma in 621 Sweden. Biomed Res Int. 2015;2015:456040.

622 [53] TNM stage group by CCG by tumour type for 10 tumour types, 2013. 3 ed: National

623 Cancer Intelligence Network; 2013.

624 [54] Violette P, Abourbih S, Szymanski KM, Tanguay S, Aprikian A, Matthews K, et al. Solitary 625 solid renal mass: can we predict malignancy? BJU Int. 2012;110:E548-52. 
626 [55] Thompson RH, Kurta JM, Kaag M, Tickoo SK, Kundu S, Katz D, et al. Tumor size is

627 associated with malignant potential in renal cell carcinoma cases. J Urol. 2009;181:2033-6.

628 [56] Frank I, Blute ML, Cheville JC, Lohse CM, Weaver AL, Zincke H. Solid renal tumors: an

629 analysis of pathological features related to tumor size. J Urol. 2003;170:2217-20.

630 [57] Dabestani S, Thorstenson A, Lindblad P, Harmenberg U, Ljungberg B, Lundstam S. Renal

631 cell carcinoma recurrences and metastases in primary non-metastatic patients: a

632 population-based study. World J Urol. 2016;34:1081-6.

633 [58] Pierorazio PM, Johnson MH, Patel HD, Sozio SM, Sharma R, Iyoha E, et al. Management

634 of Renal Masses and Localized Renal Cancer. Rockville (MD)2016.

635 [59] Marschner N, Staehler M, Muller L, Nusch A, Harde J, Koska M, et al. Survival of Patients

636 With Advanced or Metastatic Renal Cell Carcinoma in Routine Practice Differs From That in

637 Clinical Trials-Analyses From the German Clinical RCC Registry. Clin Genitourin Cancer.

638 2017;15:e209-e15.

639 [60] Heng DY, Choueiri TK, Rini BI, Lee J, Yuasa T, Pal SK, et al. Outcomes of patients with

640 metastatic renal cell carcinoma that do not meet eligibility criteria for clinical trials. Ann

641 Oncol. 2014;25:149-54.

642 [61] Ruiz-Morales JM, Swierkowski M, Wells JC, Fraccon AP, Pasini F, Donskov F, et al. First-

643 line sunitinib versus pazopanib in metastatic renal cell carcinoma: Results from the

644 International Metastatic Renal Cell Carcinoma Database Consortium. Eur J Cancer.

$645 \quad 2016 ; 65: 102-8$.

646 [62] Wells JC, Stukalin I, Norton C, Srinivas S, Lee JL, Donskov F, et al. Third-line Targeted

647 Therapy in Metastatic Renal Cell Carcinoma: Results from the International Metastatic Renal

648 Cell Carcinoma Database Consortium. Eur Urol. 2017;71:204-9. 
649 [63] Ko JJ, Choueiri TK, Rini BI, Lee JL, Kroeger N, Srinivas S, et al. First-, second-, third-line 650 therapy for mRCC: benchmarks for trial design from the IMDC. Br J Cancer. 2014;110:191765122.

652 [64] Beisland C, Johannesen TB, Klepp O, Axcrona U, Torgersen KM, Kowalski J, et al. Overall 653 survival in renal cell carcinoma after introduction of targeted therapies: a Norwegian 654 population-based study. Onco Targets Ther. 2017;10:371-85.

655 [65] Purmonen T, Martikainen JA, Soini EJ, Kataja V, Vuorinen RL, Kellokumpu-Lehtinen PL. 656 Economic evaluation of sunitinib malate in second-line treatment of metastatic renal cell 657 carcinoma in Finland. Clin Ther. 2008;30:382-92.

658 [66] Ljungberg B, Gudmundsson E, Christensen S, Lundstam S, Swedish Kidney Cancer

659 Quality Register G. Practice patterns for the surgical treatment of T1 renal cell carcinoma: a 660 nationwide population-based register study. Scand J Urol. 2014;48:445-52.

661 [67] The British Association of Urological Surgeons section of oncology analyses of 662 nephrectomies performed between January 1st and December 31st 2016. 2017. 663 [68] Aizer AA, Urun Y, McKay RR, Kibel AS, Nguyen PL, Choueiri TK. Cytoreductive 664 nephrectomy in patients with metastatic non-clear-cell renal cell carcinoma (RCC). BJU Int. 665 2014;113:E67-74.

666 [69] Psutka SP, Kim SP, Gross CP, Van Houten H, Thompson RH, Abouassaly R, et al. The 667 impact of targeted therapy on management of metastatic renal cell carcinoma: trends in 668 systemic therapy and cytoreductive nephrectomy utilization. Urology. 2015;85:442-50. 669 [70] Conti SL, Thomas IC, Hagedorn JC, Chung BI, Chertow GM, Wagner TH, et al. Utilization 670 of cytoreductive nephrectomy and patient survival in the targeted therapy era. Int J Cancer. $671 \quad 2014 ; 134: 2245-52$. 
672 [71] Tsao CK, Small AC, Kates M, Moshier EL, Wisnivesky JP, Gartrell BA, et al. Cytoreductive 673 nephrectomy for metastatic renal cell carcinoma in the era of targeted therapy in the United 674 States: a SEER analysis. World J Urol. 2013;31:1535-9.

675 [72] Patel MI, Beattie K, Bang A, Gurney H, Smith DP. Cytoreductive nephrectomy for 676 metastatic renal cell carcinoma: inequities in access exist despite improved survival. Cancer 677 Med. 2017;6:2188-93.

678 [73] Hanna N, Sun M, Meyer CP, Nguyen PL, Pal SK, Chang SL, et al. Survival Analyses of 679 Patients With Metastatic Renal Cancer Treated With Targeted Therapy With or Without 680 Cytoreductive Nephrectomy: A National Cancer Data Base Study. J Clin Oncol. 2016;34:326768175.

682 [74] Jeldres C, Baillargeon-Gagne S, Liberman D, Isbarn H, Capitanio U, Shariat SF, et al. A 683 population-based analysis of the rate of cytoreductive nephrectomy for metastatic renal cell 684 carcinoma in the United States. Urology. 2009;74:837-41.

685 [75] Dabestani S, Beisland C, Stewart GD, Bensalah K, Gudmundsson E, Lam TB, et al. Long686 term Outcomes of Follow-up for Initially Localised Clear Cell Renal Cell Carcinoma: RECUR 687 Database Analysis. Eur Urol Focus. 2018.

688 [76] Maroun R, Mitrofan L, Benjamin L, Nachbaur G, Maunoury F, Le Jeunne P, et al. Real life 689 patterns of care and progression free survival in metastatic renal cell carcinoma patients: 690 retrospective analysis of cross-sectional data. BMC Cancer. 2018;18:214.

691 [77] Edwards SJ, Wakefield V, Cain P, Karner C, Kew K, Bacelar M, et al. Axitinib, 692 cabozantinib, everolimus, nivolumab, sunitinib and best supportive care in previously 693 treated renal cell carcinoma: a systematic review and economic evaluation. Health Technol 694 Assess. 2018;22:1-278. 
695 [78] Kilonzo M, Hislop J, Elders A, Fraser C, Bissett D, McClinton S, et al. Pazopanib for the

696 first-line treatment of patients with advanced and/or metastatic renal cell carcinoma : a

697 NICE single technology appraisal. Pharmacoeconomics. 2013;31:15-24.

698 [79] Harrison MR, Hirsch BR, George DJ, Walker MS, Chen C, Korytowsky B, et al. Real-world

699 outcomes in metastatic renal cell carcinoma: insights from a Joint Community-Academic

700 Registry. J Oncol Pract. 2014;10:e63-72.

701 [80] Hawkins R. FK, Hurst M., Gordon J., Naicker N., Wang M. Estimating health outcomes in

702 real world patients with advanced or metastatic renal cell carcinoma treated with targeted

703 systemic therapy. 13th European International Kidney Cancer Symposium. Prague, Czech

704 Republic2018.

705 [81] Amdahl J, Diaz J, Sharma A, Park J, Chandiwana D, Delea TE. Cost-effectiveness of

706 pazopanib versus sunitinib for metastatic renal cell carcinoma in the United Kingdom. PLoS

707 One. 2017;12:e0175920.

708 [82] Motzer RJ, Hutson TE, Cella D, Reeves J, Hawkins R, Guo J, et al. Pazopanib versus

709 sunitinib in metastatic renal-cell carcinoma. N Engl J Med. 2013;369:722-31.

710 [83] Fife K. CJ, Nolasco S., Matakidou A., Welsh A., Eisen T. Metastatic renal cancer; How

711 many patients are we treating? National Cancer Research Institute (NCRI) Cancer

712 Conference2018.

713 [84] Systemic Anti-Cancer Therapy (SACT) Chemotherapy Dataset. In: England PH,

714 editor.2018.

715 [85] Camp C, O'Hara J, Hughes D, Adshead J. Short-term Outcomes and Costs Following

716 Partial Nephrectomy in England: A Population-based Study. Eur Urol Focus. 2017.

717 [86] British National Formulary (BNF). In: Committee JF, editor. 74 ed. London: BMJ Group

718 and Pharmaceutical Press; 2017. 
719 [87] NICE. NICE technology appraisal TA432: Everolimus for advanced renal cell carcinoma

720 after previous treatment 2017.

721 [88] NICE. NICE technology appraisal TA333: Axitinib for treating advanced renal cell

722 carcinoma after failure of prior systemic treatment. 2013.

723 [89] NICE. NICE technology appraisal guidance TA463. Cabozantinib for previously treated 724 advanced renal cell carcinoma. 2017.

725 [90] NICE. NICE technology appraisal TA417: Nivolumab for previously treated advanced 726 renal cell carcinoma. 2016.

727 [91] NICE. NICE technology appraisal TA498: Lenvatinib with everolimus for previously 728 treated advanced renal cell carcinoma. 2018.

[92] Curtis L BA. Unit Costs of Health and Social Care 2016. . Canterbury: Personal Social

730 Services Research Unit, University of Kent; 2016.

731 [93] Klinghoffer Z, Tarride JE, Novara G, Ficarra V, Kapoor A, Shayegan B, et al. Cost-utility 732 analysis of radical nephrectomy versus partial nephrectomy in the management of small 733 renal masses: Adjusting for the burden of ensuing chronic kidney disease. Can Urol Assoc J.

$734 \quad 2013 ; 7: 108-13$.

735 [94] Thompson Coon J, Hoyle M, Green C, Liu Z, Welch K, Moxham T, et al. Bevacizumab, 736 sorafenib tosylate, sunitinib and temsirolimus for renal cell carcinoma: a systematic review 737 and economic evaluation. Health Technol Assess. 2010;14:1-184, iii-iv.

738 [95] Motzer RJ, Hutson TE, Tomczak P, Michaelson MD, Bukowski RM, Rixe O, et al. Sunitinib 739 versus interferon alfa in metastatic renal-cell carcinoma. N Engl J Med. 2007;356:115-24.

740 [96] Motzer RJ, Michaelson MD, Redman BG, Hudes GR, Wilding G, Figlin RA, et al. Activity 741 of SU11248, a multitargeted inhibitor of vascular endothelial growth factor receptor and 
742 platelet-derived growth factor receptor, in patients with metastatic renal cell carcinoma. J

743 Clin Oncol. 2006;24:16-24.

744 [97] Remak E, Charbonneau C, Negrier S, Kim ST, Motzer RJ. Economic evaluation of

745 sunitinib malate for the first-line treatment of metastatic renal cell carcinoma. J Clin Oncol.

$746 \quad 2008 ; 26: 3995-4000$.

747 [98] Calvo Aller E, Maroto P, Kreif N, Gonzalez Larriba JL, Lopez-Brea M, Castellano D, et al.

748 Cost-effectiveness evaluation of sunitinib as first-line targeted therapy for metastatic renal

749 cell carcinoma in Spain. Clin Transl Oncol. 2011;13:869-77.

750

751 